\title{
SCREENING OF TEN HERBAL EXTRACTS TO COMPARE AND INVESTIGATE EFFECT ON GLUCOSE LOWERING AND ANOREXIC ACTIVITY IN WISTAR RATS
}

\author{
DEEPTI KAUSHALKUMAR JANI ${ }^{1 *}$, SUNITA GOSWAMI ${ }^{2}$ \\ ${ }^{1}$ Department of Pharmacology, Babaria Institute of Pharmacy, Varnama, Vadodara, Gujarat, India. ${ }^{2}$ Department of Pharmacology, \\ L.M. College of Pharmacy, Ahmadabad, Gujarat, India. Email: deeptijani.bip@bitseducampus.ac.in
}

Received: 21 June 2017, Revised and Accepted: 23 August 2017

\section{ABSTRACT}

Objective: Metabolic disorders are of growing concern with increasing quest for herbal medicines as a treatment option. The current study is planned to screen 10 herbal extracts, prepared from various parts of six herbal plants, to compare and investigate their antihyperglycemic and anorexic potential.

Methods: The qualitative phytochemical investigation was done as per the standard procedures. Acute oral toxicity study performed as per the Organization for Economic Co-operation and Development 420 guideline. Method optimization of glucose tolerance test (GTT) was done to select appropriate glucose load to induce hyperglycemia. Antihyperglycemic activity was evaluated by GTT (single dose and multiple dose study) and food intake inhibitory potential was screened by food intake measurement.

Results: All herbs were found safe in acute oral toxicity study. GTT method optimization study signaled use of $3 \mathrm{~g} / \mathrm{kg}$ glucose load for induction of hyperglycemia in single- and multiple-dose studies. In single-dose study, Luffa acutangula fruit extract and in multiple dose study, Solanum melongena, Moringa Oleifera, and Ricinus communis extracts were found to produce a significant glucose lowering effect as compared to the glucose control group. Results of food intake measurement showed significant appetite suppression with extracts of W. somnifera, S. melongena, M. oleifera, and R. communis.

Conclusion: The present study throws light on the effectiveness of experimental herbal extracts as antihyperglycemic and anorexic agents. This also helps in identifying potent indigenous herbs for further study.

Keywords: Glucose tolerance test, Herbal medicine, Hyperglycemia.

(C) 2017 The Authors. Published by Innovare Academic Sciences Pvt Ltd. This is an open access article under the CC BY license (http://creativecommons. org/licenses/by/4. 0/) DOI: http://dx.doi.org/10.22159/ajpcr.2017.v10i12.20869

\section{INTRODUCTION}

Metabolic disorders such as diabetes and obesity are associated with insulin resistance result into hyperglycemia. Hyperglycemia is the main characteristic symptom of diabetes mellitus [1]. Hyperglycemia contributes to the poor quality of life, reduced life expectancy, and leads to the elevated medical costs [2] and another point of concern is adverse effects associated with currently available synthetic anti-diabetic drugs [3]. Hyperglycemia leads to 3.7 million deaths per year [4], which indicates need to search for new drugs as a treatment option.

Overeating leads to the disease such as obesity [5]. As worldwide, more than $70 \%$ of adult population is overweight [4], so the eating disorders are of growing concern. Drugs such as fenfluramine, rimonabant, and sibutramine were approved due to their appetite depressant potential, but these drugs were withdrawn from the market due to their psychological and cardiovascular adverse effects [6], indicating that investigations should be done to find out a safer appetite suppressant.

Herbal medicines are a safe and effective option with fewer side effects [7]. There are so many herbal extracts screened till date for the treatment of the metabolic disorders such as diabetes and obesity. Many of them are well known as per Ayurvedic, Unani, or Siddha system of medication. These well-known plants were studied in depth for their potential to treat metabolic diseases significantly. On the other side, there are so many herbal extracts studied briefly for the treatment of few or any one condition associated with metabolic disorders. In this study, such herbal extracts are chosen to evaluate and compare their antihyperglycemic and appetite depressants potential. The plants selected for the study are Luffa acutangula (L.) Roxb., Raphanus sativus Linn., Withania somnifera (L.) Dunal, Ricinus communis Linn., Solanum melongena Linn., and Moringa oleifera Linn. Azadirachta indica, A. Juss is chosen to study as herbal standard (Fig. 1).

\section{MATERIALS AND METHODS}

\section{Materials used}

Accu-Chek ${ }^{\circledR}$ active Glucometer (Roche Diagnostics, Germany) was purchased with Accu-Chek ${ }^{\circledR}$ active strips. Metformin (Glucophage, Sun Pharmaceutical Industries Ltd., Vadodara, India) and Rimonabant (Gift Sample from Cadila Healthcare Ltd., India) were used as standard drug. Herbal plants were collected by field collection.

\section{Experimental animals and ethical approval}

Wistar rats of either sex, weighing 200-250 g, were used in this study. Animals were housed under standard condition (well ventilated,

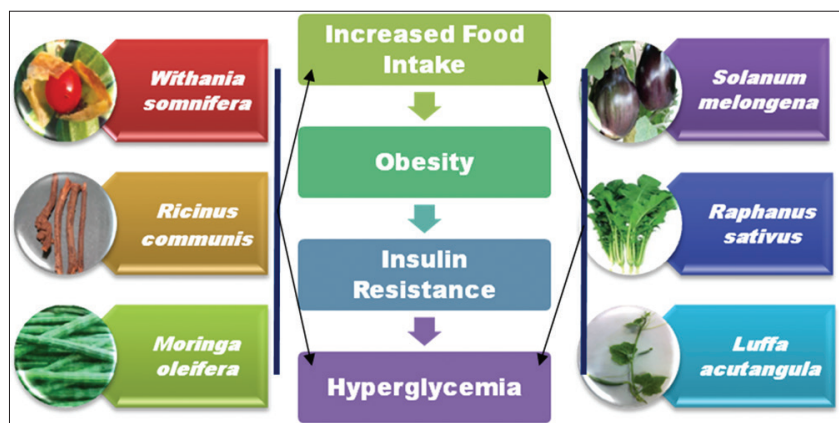

Fig. 1: Study of herbs for glucose lowering and food intake inhibitory activity 
temperature $22 \pm 2^{\circ} \mathrm{C}$, relative humidity $50-60 \%$, and $12 \mathrm{hr}$ day and night cycle). The food consisted of normal rat chow, and water was provided ad libitum. The study was conducted in accordance with the Committee for the Purpose of Control and Supervision of Experiments on Animals (CPCSEA) guidelines, Government of India. The animal study protocol was approved by IAEC committee, CPCSEA, Government of India (BIP/IAEC/2015/18).

\section{Collection and authentication of herbs}

After collection, all herbs were dried and authenticated. L. acutangula and $R$. sativus were authenticated from K.N.K. College of Horticulture, Mandsaur (M.P.), India, and authentication of W. somnifera, R. communis, $S$. melongena, $M$. oleifera, and $A$. indica was done at Department of Botany, Gujarat University, India. Dried herbs were powdered and extracted using various methods as mentioned in Table 1.

\section{Phytochemical analysis}

Preliminary qualitative phytochemical tests to identify the chemical constituents of extracts were carried out according to the standard methods [21-23].

\section{Acute oral toxicity study}

Single-dose acute oral toxicity study was performed as per the Organization for Economic Co-operation and Development 420 guidelines [24].

\section{Pharmacological screening}

For all the methods, 1\% carboxymethyl cellulose (CMC) was used as a vehicle.

The extracts used for the study are:

- $\quad$ Aqueous extracts of, $R$. sativus stem (RSSAQ), A. indica leaves (AIAQ), $W$. somnifera leaves (WSLAQ), and W. somnifera fruit (WSFAQ)

- $\quad$ Ethanolic extract of W. somnifera leaves (WSLETH)

- Methanolic extract of L. acutangula fruit (LAFMTH)

- Hydroalcoholic extracts of S. melongena fruit (SMHA), M. oleifera Pods (MOHA), R. communis roots (RCRHA), and L. acutangula peel (LAPHA).

\section{Glucose tolerance test (GTT) (method optimization)}

For method optimization study, animals were divided into four groups $(n=6)$. Group I - vehicle control was treated with 1\% CMC, orally. Group II, Group III, and Group IV were treated with different glucose loads, that is, $2 \mathrm{~g} / \mathrm{kg}, 3 \mathrm{~g} / \mathrm{kg}$, and $4 \mathrm{~g} / \mathrm{kg}$ orally, respectively. The glucose load selected after the optimization study was used for further GTT studies.

\section{GTT (single dose study)}

In this study, all the animals were divided into XIII groups $(n=6)$, that is, Group I - vehicle control (1\% CMC), Group II - glucose control (glucose, $3 \mathrm{~g} / \mathrm{kg}$ ), Group III, IV, V, VI, VII, VIII, IX, X, XI, and XII were treated with RSSAQ LAPHA, LAFMTH, WSLAQ WSLETH, WSFAQ, RCRHA, MOHA, SMHA, and AIAQ respectively, and Group XIII metformin treated $(100 \mathrm{mg} / \mathrm{kg})$. Treatments were given once orally. All the extracts were given at the dose of $400 \mathrm{mg} / \mathrm{kg}$. AIAQ was used as herbal standard and metformin as allopathic standard.

After 18 hrs of food deprivation, basal blood glucose was measured for randomization. After randomization, treatment was given to all the animals as mentioned in the group design and glucose levels were measured $1 \mathrm{hr}$ after treatment. Thereafter, oral glucose load was given to all the groups except Group I. Blood glucose levels were measured using Accu-Chek Active Glucometer Strips at 30, 60, 90, and 120 minutes after the oral glucose load [25].

\section{GTT (multiple dose study)}

In this study, all the animals were given treatment for 7 days. On the $7^{\text {th }}$ day, GTT study was performed. Animal grouping and GTT study were done same as mentioned above in GTT (single-dose study).

\section{Food intake measurement}

Animals were randomized on the basis of mean food intake $(n=3$ trials). After randomization, all animals divided into XII groups $(n=6)$, that is, Group I - vehicle control (1\% CMC), Group II, III, IV, V, VI, VII, VIII, IX, X, and XI treated with RSSAQ, LAPHA, LAFMTH, WSLAQ, WSLETH, WSFAQ, RCRHA, MOHA, SMHA, and AIAQ, respectively, and Group XII - Rimonabant-treated $(10 \mathrm{mg} / \mathrm{kg})$. All the extracts were given at the dose of $400 \mathrm{mg} / \mathrm{kg}$. All the treatments were given once orally.

Cages were prepared with normal chow and weighed. After $18 \mathrm{hrs}$ fasting, test drug or vehicle was administered orally to rats. Immediately after the treatment, the animals were put in the cages with pre-weighed feed, with free access to food and water. The rats were left in the cage for $3 \mathrm{hrs}$, and then returned to their original cages. All excrement was removed and the feed was reweighed [26].

\section{Statistical analysis}

Data analysis was done by one-way/two-way ANOVA followed by Bonferroni multiple comparison test using GraphPad Prism 5 software. The $\mathrm{p}<0.05$ was considered statistically significant. Data are presented as mean \pm standard error of the mean.

Table 1: List of study plants, extracts, extraction method, and uses

\begin{tabular}{|c|c|c|c|c|c|c|}
\hline S. No & Plant used & Plant family & $\begin{array}{l}\text { Part } \\
\text { used }\end{array}$ & Extract used & $\begin{array}{l}\text { Method of } \\
\text { extraction }\end{array}$ & Medicinal uses \\
\hline 1 & R. sativus Linn. & Brassicaceae & Stem & Aqueous & Cold maceration & $\begin{array}{l}\text { Antioxidant and radical scavenging activity [8], } \\
\text { antibacterial [9] }\end{array}$ \\
\hline 2 & $\begin{array}{l}\text { L. acutangula (L.) } \\
\text { Roxb }\end{array}$ & Cucurbitaceae & Fruit & Methanolic & Soxhletion & $\begin{array}{l}\text { Antidiabetic and antihyperlipidemic [10], } \\
\text { antioxidant [11] }\end{array}$ \\
\hline 3 & & & Peel & Hydro-alcoholic & Cold maceration & $\alpha$-amylase inhibitory activity [12] \\
\hline 4 & W. somnifera (L.) & Solanaceae & Leaf & Ethanolic & Soxhletion & Hypoglycemic and hypolipidemic [13], \\
\hline 6 & & & Fruit & Aqueous & Cold maceration & Antioxidant [14] \\
\hline 7 & M. oleifera Linn. & Moringaceae & Pod & Hydroalcoholic & Soxhletion & $\begin{array}{l}\text { Antihypertensive, cholesterol lowering, antidiabetic, } \\
\text { hepatoprotective [15], antioxidant [16] }\end{array}$ \\
\hline 8 & S. melongena Linn. & Solanaceae & Fruit & Hydroalcoholic & Soxhletion & Cholesterol lowering [17], antioxidant [18] \\
\hline 9 & R. communis Linn. & Euphorbiaceae & Root & Hydroalcoholic & Soxhletion & $\begin{array}{l}\text { Anti-inflammatory and free radical scavenging } \\
\text { activity [19] }\end{array}$ \\
\hline 10 & A. indica A. Juss & Meliaceae & Leaf & Aqueous & Cold maceration & Antihyperglycemic [20] \\
\hline
\end{tabular}

R. sativus: Raphanus sativus, L. acutangula: Luffa acutangula, W. somnifera: Withania somnifera, M. oleifera: Moringa oleifera, S. melongena: Solanum melongena,

R. communis: Ricinus communis, A. indica: Azadirachta indica 


\section{RESULTS}

Phytochemical analysis

Results of qualitative phytochemical analysis of the extracts showed the presence of flavonoids, glycosides, saponins, and/or tannins.

\section{Acute oral toxicity study}

No sign of toxicity was observed during toxicity study. Necropsy study revealed that structure abnormality was found to be absent.

GTT (method optimization)

On the basis of the results obtained, $2 \mathrm{~g} / \mathrm{kg}, 3 \mathrm{~g} / \mathrm{kg}$, and $4 \mathrm{~g} / \mathrm{kg}$ glucose load were found to increase glucose levels significantly as compared to vehicle control. Readings of the area under the curve $\left(\mathrm{AUC}_{0-120}\right)$ of delta glucose indicated a significant increase in $\mathrm{AUC}_{0-120}$ of glucose loaded groups as compared to vehicle control (Fig. 2).

glucose in Wistar rats). Values are expressed as mean \pm standard error of the mean $(n=6)$. Data are analyzed by one-way ANOVA followed by Bonferroni multiple comparison test. ${ }^{* * *} \mathrm{p}<0.001$ as compared to Group I

\section{GTT (Single-dose study)}

Results indicate that significant elevation in glucose level was observed at $30,60,90$, and 120 minutes in glucose control group as compared to vehicle control (Table 2). In treatment groups, LAPHA-treated group showed decreased glucose levels at 30 minutes with a significant increase at 60 minutes when compared with the glucose control. LAFMTH-treated group showed a significant decrease in glucose levels at 30 minutes, as compared to glucose control. WSLAQ group showed a significant increase in glucose level at 30,60, and 90 minutes and WSLETH group showed a significant increase in glucose level at 30 minutes, as compared to the glucose control group. No significant change was observed in RSSAQ-, WSFAQ-, RCRHA-, MOHA-, and SMHAtreated groups. AIAQ-treated group showed significant, increase in glucose level at 30 minutes and decrease at 60 minutes as compared to glucose control. Metformin-treated group showed a significant decrease in glucose level at 30,60, 90, and 120 minutes as compared to glucose control. $\mathrm{AUC}_{0-120}$ readings of delta blood glucose indicated a significant increase in $\mathrm{AUC}_{0-120}$ of glucose-treated group as compared to vehicle control group. A significant increase in $\mathrm{AUC}_{0-120}$ of WSLAQ group was observed while a significant decrease was observed in $\mathrm{AUC}_{0-120}$ of metformin-treated group as compared to glucose control group (Fig. 3).

\section{GTT (multiple-dose study)}

The results (Table 3) indicate that significant elevation in glucose level was observed at 30,60, and 90 minutes in glucose control group as compared to vehicle control. In treatment groups, a significant decrease in glucose level was observed in RCRHA-, SMHA-, and metformin-treated groups at 30 and 60 minutes and in LAPHA- and MOHA-treated group at 30 minutes, when compared with glucose control. A significant increase in glucose level was observed in RSSAQ-, LAFMTH-, WSLAQ-, WSLETH-, and AIAQ-treated groups at 120 minutes and in LAPHA-treated group

Table 2: Blood glucose levels at various time points in GTT (single-dose study)

\begin{tabular}{|c|c|c|c|c|c|c|}
\hline \multirow[t]{2}{*}{ Group } & \multicolumn{6}{|c|}{ Blood glucose concentration in $\mathrm{mg} / \mathrm{dl}($ mean \pm SEM) } \\
\hline & Basal (minute) & O minute & 30 minutes & 60 minutes & 90 minutes & 120 minutes \\
\hline I. Vehicle control & $83.2 \pm 2.2$ & $86 \pm 2.3$ & $93.7 \pm 2.9$ & $85.8 \pm 1.4$ & $77.5 \pm 2.8$ & $74.7 \pm 1.7$ \\
\hline II. Glucose control (3 g/kg) & $87.3 \pm 1.8$ & $91.7 \pm 1.9$ & $149.8 \pm 6^{+++}$ & $138.5 \pm 5.9^{+++}$ & $118.5 \pm 5^{+++}$ & $105.3 \pm 8^{++}$ \\
\hline III. Glucose+RSSAQ & $82.8 \pm 2.7$ & $85.7 \pm 2.4$ & $135 \pm 10.8$ & $133.8 \pm 5.6$ & $116 \pm 5.7$ & $110.5 \pm 7.4$ \\
\hline IV. Glucose+LAPHA & $83 \pm 2.9$ & $86 \pm 3.9$ & $107.8 \pm 4.5^{* * *}$ & $183 \pm 9.79 * * *$ & $124.7 \pm 12$ & $96 \pm 6.4$ \\
\hline V. Glucose+LAFMTH & $81.5 \pm 2.1$ & $94.3 \pm 2.7$ & $121 \pm 2.9^{* *}$ & $122.7 \pm 5.4$ & $113 \pm 6.3$ & $99 \pm 4.7$ \\
\hline VI. Glucose+WSLAQ & $84 \pm 2.4$ & $76 \pm 0.9$ & $285 \pm 16.8^{* * *}$ & $273.3 \pm 12^{* * *}$ & $161 \pm 9.4^{* * *}$ & $108.5 \pm 8.3$ \\
\hline VII. Glucose+WSLETH & $84.7 \pm 1.4$ & $75 \pm 2.5$ & $176 \pm 8.9^{* *}$ & $123.7 \pm 3.9$ & $108 \pm 4.1$ & $96 \pm 2.2$ \\
\hline VIII. Glucose+WSFAQ & $93.8 \pm 5.1$ & $95.7 \pm 4.5$ & $136.5 \pm 3.8$ & $140.2 \pm 4.3$ & $115.3 \pm 3$ & $104.8 \pm 4.1$ \\
\hline IX. Glucose+RCRHA & $90.5 \pm 3.4$ & $94.3 \pm 3.7$ & $134.2 \pm 3.2$ & $138.3 \pm 2.2$ & $122.2 \pm 2.8$ & $106.8 \pm 2.1$ \\
\hline X. Glucose+MOHA & $92.5 \pm 1.8$ & $93 \pm 2$ & $155.2 \pm 4.1$ & $135.2 \pm 2.6$ & $130.3 \pm 2.5$ & $118.8 \pm 1.7$ \\
\hline XI. Glucose+SMHA & $91.5 \pm 1.4$ & $94.2 \pm 1.8$ & $135.7 \pm 1.5$ & $123.5 \pm 1.8$ & $122.7 \pm 1.4$ & $111.7 \pm 1.5$ \\
\hline XII. Glucose+AIAQ & $83.5 \pm 1.2$ & $101.9 \pm 2.6$ & $181 \pm 3^{* * *}$ & $111.5 \pm 2^{* *}$ & $110 \pm 4.1$ & $99.9 \pm 4.5$ \\
\hline XIII. Glucose+Metformin & $89.7 \pm 1.8$ & $75 \pm 0.97$ & $91.7 \pm 3.9^{* * *}$ & $105 \pm 4.7^{* * *}$ & $98.5 \pm 3.6^{*}$ & $85.2 \pm 3.5^{*}$ \\
\hline
\end{tabular}

Values are expressed as mean \pm SEM $(\mathrm{n}=6)$. Data are analyzed by two-way ANOVA followed by Bonferroni multiple comparison test. ${ }^{+++} \mathrm{p}<0.001$ as compared to Group I, ${ }^{*} \mathrm{p}<0.05,{ }^{* *} \mathrm{p}<0.01$, and ${ }^{* * *} \mathrm{p}<0.001$ as compared to Group II. GTT: Glucose tolerance test, SEM: Standard error of the mean, RSSAQ: Aqueous extract of Raphanus sativus stem, AIAQ: Aqueous extract of Azadirachta indica leaves, WSLAQ: Aqueous extract of Withania somnifera leaves, WSFAQ: Aqueous extract of Withania somnifera fruit, WSLETH: Ethanolic extract of Withania somnifera leaves, LAFMTH: Methanolic extract of Luffa acutangula fruit, SMHA: Hydroalcoholic extract of Solanum melongena fruit, MOHA: Hydroalcoholic extract of Moringa oleifera pods, RCRHA: Hydroalcoholic extract of Ricinus communis roots, LAPHA: Hydroalcoholic extract of Luffa acutangula peel

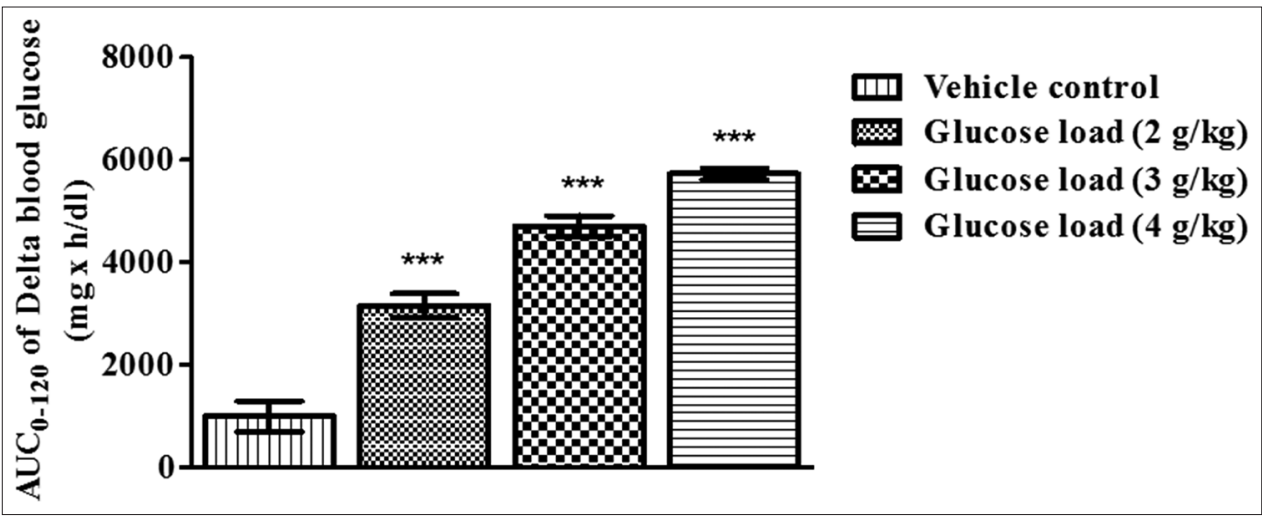

Fig. 2: Glucose tolerance test-method optimization (AUC ${ }_{0-120}$ of the delta glucose in Wistar rats). Values are expressed as mean \pm standard error of the mean $(n=6)$. Data were analyzed by one-way ANOVA followed by Bonferroni multiple comparison test. $* * *$ p $<0.001$ as compared to Group I 


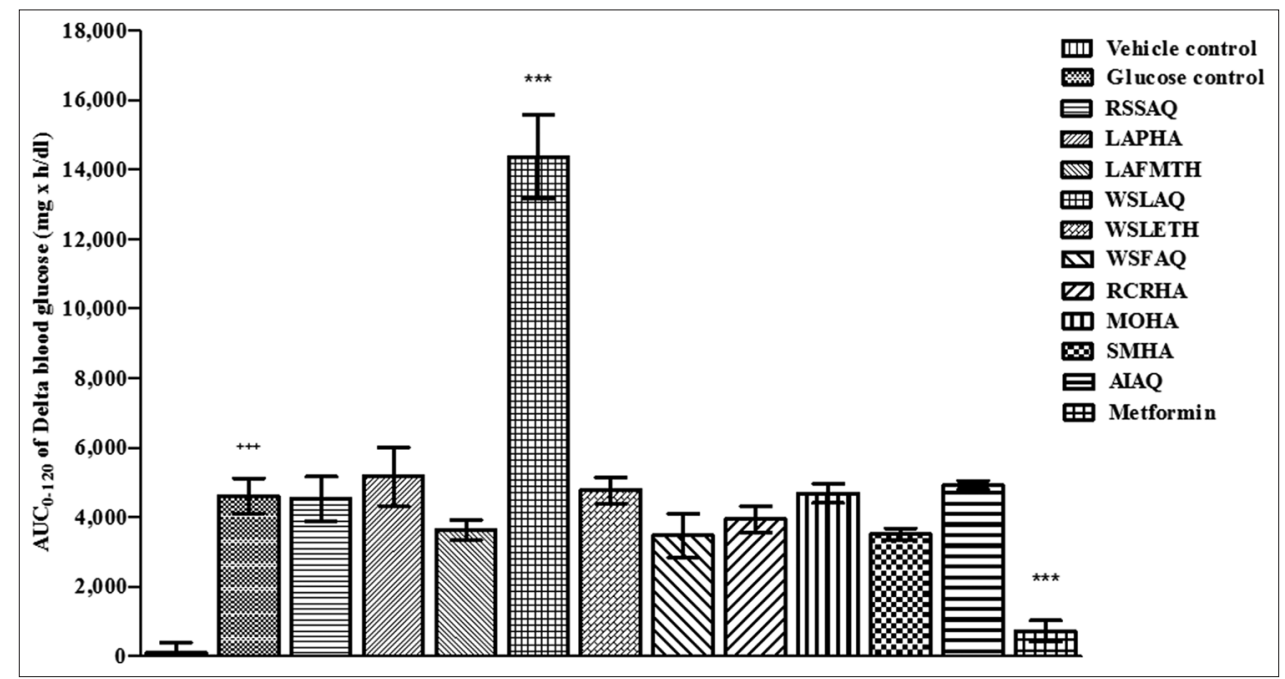

Fig. 3: Glucose tolerance test - single-dose study $\left(\mathrm{AUC}_{0-120}\right.$ of the delta blood glucose in Wistar rats). Values are expressed as mean \pm standard error of the mean $(n=6)$. Data were analyzed by one-way ANOVA followed by Bonferroni multiple comparison test. ${ }^{++} p<0.001$ as compared to Group I, ${ }^{* * *} \mathbf{p}<0.001$ as compared to Group II

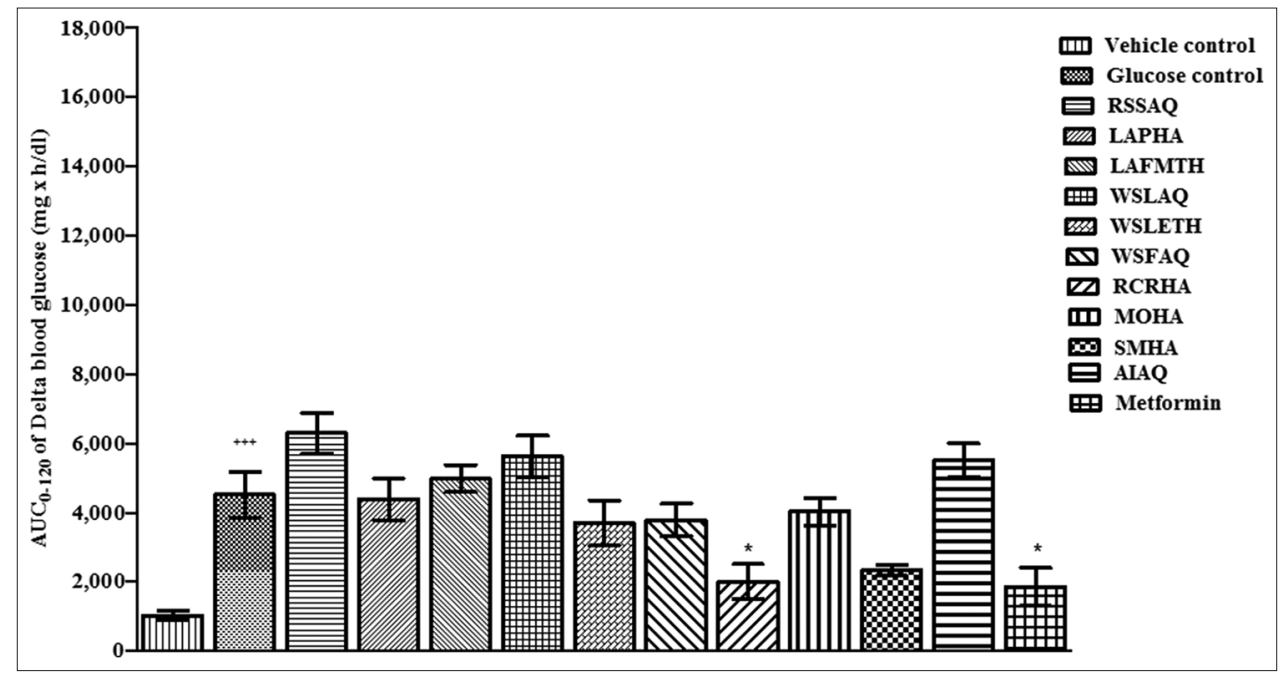

Fig. 4: Glucose tolerance test - multiple-dose study $\left(\mathrm{AUC}_{0-120}\right.$ of the delta blood glucose in Wistar rats). Values are expressed as mean \pm standard error of the mean $(n=6)$. Data were analyzed by one-way ANOVA followed by Bonferroni multiple comparison test. ${ }^{++} p<0.001$ as compared to Group I, *p<0.05 as compared to Group II

at 60 minutes, as compared to glucose control group. No significant change was observed in WSFAQ-treated group. $\mathrm{AUC}_{0-120}$ readings of delta blood glucose (Fig. 4) indicated a significant increase in $\mathrm{AUC}_{0-120}$ of glucose control group as compared to the vehicle control group, whereas a significant decrease was observed in $\mathrm{AUC}_{0-120}$ of RCRHA and metformin-treated groups as compared to the glucose control group.

Food intake measurement

Results indicate that the order of $\%$ inhibition of food intake is:

Rimonabant $>$ WSLETH $>$ SMHA $>$ RCRHA $>$ WSFAQ $>$ WSLAQ $>$ MOHA $>$ LAPHA $>$ RSSAQ.

No effect on food intake inhibition was observed in LAFMTH- and AIAQtreated groups (Fig. 5).

\section{DISCUSSION}

GTT was developed with the aim to diagnose glucose intolerance and type 2 diabetes. This test also determines the tissue insulin sensitivity $[27,28]$. However, as per the pre-clinical studies were done, GTT is used as a well-known preliminary screening method for detection of the antihyperglycemic potential of drugs in non-diabetic animals. In the current study, drugs were screened using various GTT models to estimate the possibility of use in diabetes.

Safety of selected plant extracts was confirmed by results of acute oral toxicity study. In single-dose and multiple-dose GTT models; hyperglycemia was significantly well controlled at various time points in L. acutangula fruit extract and S. melongena, M. oleifera, and R. communis extracts treated groups, respectively, which indicates that these extracts enhance glucose utilization. The possible reason for glucose lowering activities of these plant extracts may be the presence of flavonoids in all the extracts. It is reported that flavonoids have hypoglycemic property [29] and exert a stimulatory effect on insulin secretion, improve hyperglycemia, and increase glucose uptake in skeletal muscles [30]. Agwaya et al. discussed that medicinal plants possess hypoglycemic activity through various mechanisms including improvement in the insulin sensitivity of target cells or augmenting glucose-dependent insulin secretion. They suggested that active phytochemical compounds can produce action through a variety of mechanisms [31] 
Table 3: Blood glucose levels at various time points in GTT (multiple dose study)

\begin{tabular}{|c|c|c|c|c|c|c|}
\hline \multirow[t]{2}{*}{ Group } & \multicolumn{6}{|c|}{ Blood glucose concentration in $\mathrm{mg} / \mathrm{dl}($ mean \pm SEM) } \\
\hline & Basal (minute) & 0 minute & 30 minutes & 60 minutes & 90 minutes & 120 minutes \\
\hline I. Vehicle control & $83 \pm 2.5$ & $90.7 \pm 2.6$ & $97.7 \pm 8$ & $94.8 \pm 3.6$ & $90.7 \pm 2.2$ & $83.3 \pm 4.7$ \\
\hline III. Glucose+RSSAQ & $74.8 \pm 3.4$ & $104.3 \pm 8.7$ & $137.7 \pm 5.4$ & $135.2 \pm 5.5$ & $134.8 \pm 3.9$ & $128.3 \pm 3.6^{* *}$ \\
\hline IV. Glucose+LAPHA & $89 \pm 1.15$ & $84.17 \pm 3.3$ & $119.3 \pm 4.1^{*}$ & $188 \pm 8^{* * *}$ & $107.7 \pm 9.5$ & $84.7 \pm 2.97$ \\
\hline V. Glucose+LAFMTH & $88.8 \pm 3.6$ & $101.3 \pm 3.6$ & $154.7 \pm 6.5$ & $132.5 \pm 6.2$ & $123.5 \pm 5.7$ & $132.5 \pm 4.9^{* * *}$ \\
\hline VI. Glucose+WSLAQ & $81.67 \pm 6.4$ & $104 \pm 10.3$ & $138.3 \pm 10$ & $133.7 \pm 15$ & $133.3 \pm 7.3$ & $135.8 \pm 6.5^{* * *}$ \\
\hline VII. Glucose+WSLETH & $97.3 \pm 3.6$ & $89.5 \pm 3.1$ & $135.8 \pm 2.7$ & $135 \pm 4.4$ & $129.5 \pm 5.4$ & $127.3 \pm 4^{* *}$ \\
\hline VIII. Glucose+WSFAQ & $90.67 \pm 4$ & $94 \pm 4.6$ & $139.5 \pm 3.1$ & $132.3 \pm 4.8$ & $119.2 \pm 5.8$ & $104.8 \pm 4.1$ \\
\hline IX. Glucose+RCRHA & $91.8 \pm 3.7$ & $75.3 \pm 2$ & $113 \pm 2.1^{* *}$ & $106.7 \pm 9.1^{* * *}$ & $117.8 \pm 6.3$ & $101.5 \pm 5.2$ \\
\hline X. Glucose+MOHA & $81.5 \pm 1.98$ & $74.17 \pm 1.5$ & $117.5 \pm 4.6^{*}$ & $139.5 \pm 6.4$ & $114.17 \pm 5$ & $96.17 \pm 2.5$ \\
\hline XI. Glucose+SMHA & $87.3 \pm 2.38$ & $79.7 \pm 2.9$ & $117.7 \pm 3.7^{*}$ & $121.3 \pm 5.7^{* *}$ & $99.67 \pm 1.5$ & $89.5 \pm 1.86$ \\
\hline XII. Glucose+AIAQ & $79 \pm 3.3$ & $81 \pm 2.85$ & $130.7 \pm 5.6$ & $130 \pm 4.4$ & $133.17 \pm 4$ & $132.7 \pm 4.8^{* * *}$ \\
\hline XIII. Glucose+Metformin & $85.17 \pm 4.5$ & $74.5 \pm 3.1$ & $108.3 \pm 4.7^{* * *}$ & $103 \pm 6.9^{* * *}$ & $99.7 \pm 7.16$ & $97.5 \pm 7.78$ \\
\hline
\end{tabular}

Values are expressed as mean \pm SEM $(n=6)$. Data analyzed by two-way ANOVA followed by Bonferroni multiple comparison test. ${ }^{++} \mathrm{p}<0.01$ and ${ }^{+++} \mathrm{p}<0.001$ as compared to Group I, ${ }^{*} \mathrm{p}<0.05,{ }^{* *} \mathrm{p}<0.01$ and ${ }^{* * *} \mathrm{p}<0.001$ as compared to Group II. GTT: Glucose tolerance test, SEM: Standard error of the mean, RSSAQ: Aqueous extract of Raphanus sativus stem, AIAQ: Aqueous extract of Azadirachta indica leaves, WSLAQ: Aqueous extract of Withania somnifera leaves, WSFAQ: Aqueous extract of Withania somnifera fruit, WSLETH: Ethanolic extract of Withania somnifera leaves, LAFMTH: Methanolic extract of Luffa acutangula fruit, SMHA: Hydroalcoholic extract of Solanum melongena fruit, MOHA: Hydroalcoholic extract of Moringa oleifera pods, RCRHA: Hydroalcoholic extract of Ricinus communis roots, LAPHA: Hydroalcoholic extract of Luffa acutangula peel

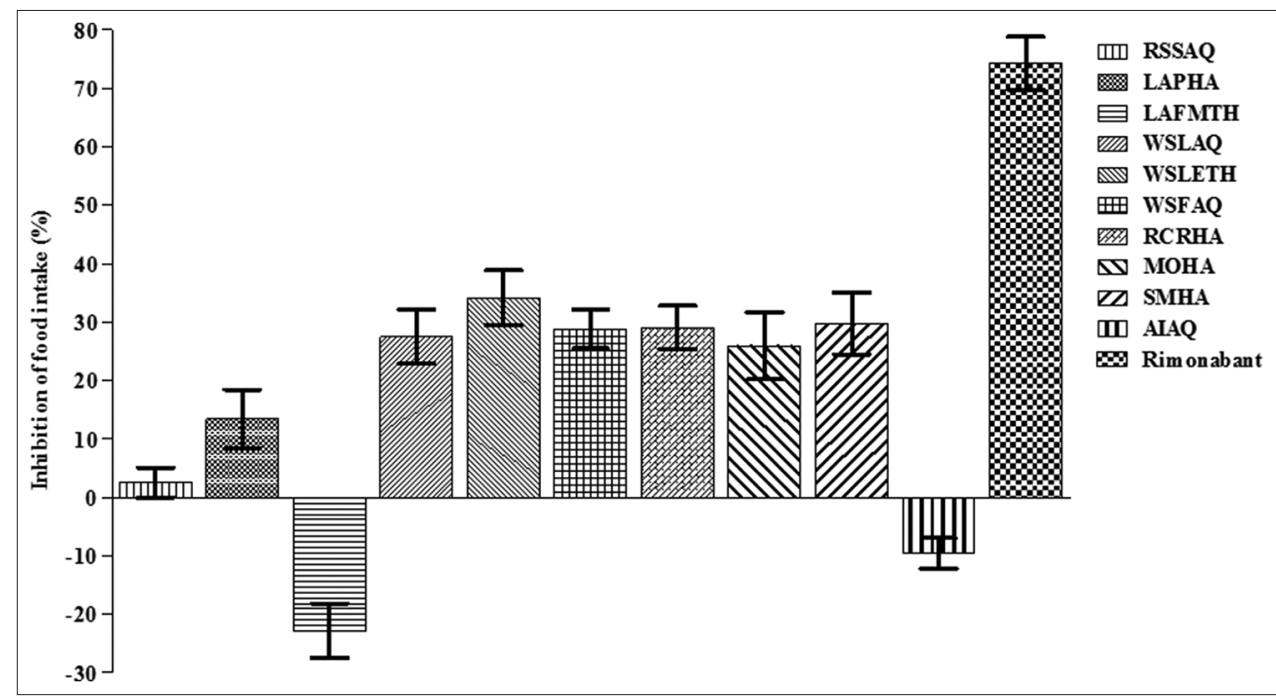

Fig. 5: Food intake inhibition (\%) after drug treatment for food intake measurement study. Values are expressed as mean \pm standard error of the mean $(n=6)$

However, few extracts fail to control glucose level, despite the presence of flavonoids, saponins, etc., as well as supporting literature, which may be because of either complex reaction between the constituents present or less amount of the desired constituent.

The drugs, approved for the treatment of obesity, have focused on the food intake inhibitory activity because of overeating as a main etiological factor responsible for obesity. Drugs such as fenfluramine, sibutramine, rimonabant, and lorcaserin reduce food intake when given acutely to lean rodents [32]. Food intake measurement is a model for screening of drugs to investigate their food intake inhibitory potential. In this model, the possible mechanism of food intake inhibition may be the action of the drug through the mediators of central nervous system or periphery.

AIAQ extract used as herbal standard on the basis of reported studies has failed to give an effective response in any of the selected model, suggesting that a detailed investigation is required to detect glucose inhibitory and food intake inhibitory potential of AIAQ extract. There is a possibility that aqueous extract may be less effective as compared to alcoholic/hydroalcoholic extracts.

\section{CONCLUSION}

The current study throws light on the selected plants for their glucose lowering and food intake inhibitory potential. Such studies help to confirm the utility of selected herbal medicines for chronic studies of metabolic disorders.

\section{ACKNOWLEDGMENT}

We express deep gratitude to the Animal Resource Department, Sun Pharma Advanced Research Center, Vadodara, India, for providing animals for research purpose. We express gratitude to Cadila healthcare, India, for providing rimonabant as a gift sample. We are thankful to Vasu Research Center, Vadodara, India, for help in herbal drug procurement.

\section{REFERENCES}

1. Pugliese A. The multiple origins of Type 1 diabetes. Diabet Med 2013;30(2):135-46.

2. Fotino N, Fotino C, Pileggi A. Re-engineering islet cell transplantation. Pharmacol Res 2015;98:76-85.

3. Stein SA, Lamos EM, Davis SN. A review of the efficacy and safety of oral antidiabetic drugs. Expert Opin Drug Saf 2013;12(2):153-75. 
4. World Health Organization. Obesity and Overweight; 2016. Available from: http:/www.who.int/mediacentre/factsheets/fs311/en.

5. Ruhm CJ. Understanding overeating and obesity. J Health Econ 2012;31(6):781-96.

6. Kang JG, Park CY. Anti-obesity drugs: A review about their effects and safety. Diabetes Metab J 2012;36:13-25.

7. Jerine PS, Evan PS. Global current trends in natural products for diabetes management: A review. Int J Pharm Pharm Sci 2016;8(4):20-8.

8. Beevi SS, Narasu ML, Gowda BB. Polyphenolics profile, antioxidant and radical scavenging activity of leaves and stem of Raphanus sativus L. Plant Foods Hum Nutr 2010;65(1):8-17.

9. Beevi SS, Mangamoori LN, Dhand V, Ramakrishna DS. Isothiocyanate profile and selective antibacterial activity of root, stem, and leaf extracts derived from Raphanus sativus L. Foodborne Pathog Dis 2009;6(1):129-36

10. Pimple BP, Kadam PV, Patil MJ. Antidiabetic and antihyperlipidemic activity of Luffa acutangula fruit extracts in streptozotocin induced NIDDM rats. Asian J Pharm Clin Res 2011;4 Suppl 2:156-63.

11. Reddy BP, Mohan SV, Sarma PN. Antioxidant and antimicrobial activity of Luffa acutangula fruit extract based on total phenolic content as index. J Chem Pharm Sci 2010;3(4):218-23.

12. Nagarajaiah SB, Prakash J. Chemical composition and bioactive potential of dehydrated peels of Benincasa hispida, Luffa acutangula, and Sechium edule. J Herbs Spices Med Plants 2015;21:193-202.

13. Udayakumar R, Kasthurirengan S, Mariashibu TS, Rajesh M, Anbazhagan VR, Kim SC, et al. Hypoglycaemic and hypolipidaemic effects of Withania somnifera root and leaf extracts on alloxan-induced diabetic rats. Int J Mol Sci 2009;10(5):2367-82.

14. Alam N, Hossain M, Mottalib MA, Sulaiman SA, Gan SH, Khalil MI. Methanolic extracts of Withania somnifera leaves, fruits and roots possess antioxidant properties and antibacterial activities. BMC Complement Altern Med 2012;12:175.

15. Anwar F, Latif S, Ashraf M, Gilani AH. Moringa oleifera: A food plant with multiple medicinal uses. Phytother Res 2007;21(1):17-25.

16. Luqman S, Srivastava S, Kumar R, Maurya AK, Chanda D. Experimental assessment of Moringa oleifera Leaf and fruit for its antistress, antioxidant, and scavenging potential using in vitro and in vivo assays. Evid Based Complement Alternat Med 2012;2012:519084.

17. Guimarães PR, Galvão AM, Batista CM, Azevedo GS, Oliveira RD, Lamounier RP, et al. Eggplant (Solanum melongena) infusion has a modest and transitory effect on hypercholesterolemic subjects. Braz J Med Biol Res 2000;33(9):1027-36.
18. Satam NK, Parab LS, Bhoir SI. HPTLC finger print analysis and antioxidant activity of flavonoid fraction of Solanum melongena Linn fruit. Int J Pharm Pharm Sci 2013;5(3):734-40.

19. Ilavarasan R, Mallika M, Venkataraman S. Anti-inflammatory and free radical scavenging activity of Ricinus communis root extract. J Ethnopharmacol 2006;103(3):478-80.

20. Chattopadhyay RR. Possible mechanism of antihyperglycemic effect of Azadirachta indica leaf extract: Part V. J Ethnopharmacol 1999;67(3):373-6.

21. Trease GE, Evans WC. Pharmacognosy. $13^{\text {th }}$ ed. London: Bailliere Tindall; 1989

22. Harborne JB. Phytochemical Methods. London: Chapman and Hall Ltd.; 1973. p. 99-188.

23. Sofowara A. Medicinal Plants and Traditional Medicine in Africa. Ibadan, Nigeria: Spectrum Books Ltd.; 1993. p. 289.

24. OECD Test 420. Acute Oral Toxicity-Fixed dose Procedure. Vol. 4. OECD Guidelines for Testing of Chemicals; 2001. p. 1-4.

25. Elberry AA, Harraz FM, Ghareib SA, Gabr SA, Nagy AA, AbdelSattar E. Methanolic extract of Marrubium vulgare ameliorates hyperglycemia and dyslipidemia in streptozotocin-induced diabetic rats. Int J Diabetes Mellitus 2015;3(1):37-44

26. Bjursell M, Egecioglu E, Gerdin AK, Svensson L, Oscarsson J, Morgan D, et al. Importance of melanin-concentrating hormone receptor for the acute effects of ghrelin. Biochem Biophys Res Commun 2005;326(4):759-65

27. Khairunisa D, Pratiwi A, Setiawan AA, Dahlan K, Kartono A. Analysis of oral glucose tolerance test using modified oral minimal model to diagnose of Type 2 diabetes. Int J Pharm Pharm Sci 2015;7(8):313-6.

28. Reaven GM, Brand RJ, Chen YD, Mathur AK, Goldfine I. Insulin resistance and insulin secretion are determinants of oral glucose tolerance in normal individuals. Diabetes 1993;42(9):1324-32.

29. Song Y, Manson JE, Buring JE, Sesso HD, Liu S. Associations of dietary flavonoids with risk of Type 2 diabetes, and markers of insulin resistance and systemic inflammation in women: A prospective study and cross-sectional analysis. J Am Coll Nutr 2005;24(5):376-84.

30. Babu PV, Liu D, Gilbert ER. Recent advances in understanding the anti-diabetic actions of dietary flavonoids. J Nutr Biochem 2013;24(11):1777-89.

31. Agwaya MS, Vuzi PC, Nandutu AM. Hypoglycemic activity of aqueous root bark extract Zanthoxylum chalybeum in alloxan-induced diabetic rats. J Diabetes Res 2016;2016:8727590.

32. Vickers SP, Jackson HC, Cheetham SC. The utility of animal models to evaluate novel anti-obesity agents. Br J Pharmacol 2011;164(4):1248-62. 